\title{
Modelling of heat transfer in a packed bed column
}

\author{
Paulina Pianko-Oprych \\ West Pomeranian University of Technology, Szczecin, Institute of Chemical Engineering and Environmental Protection Processes, \\ al. Piastow 42, 71-065 Szczecin, Poland, e-mail: Paulina.Pianko@zut.edu.pl
}

\begin{abstract}
The CFD modelling of heat transfer in the packed bed column in the laminar and turbulent flow regimes has been presented. Three numerical grids with different densities were generated for the packed bed column. The modelling was performed with the use of the Porous Media Model for treating the flow inside a porous structure. The standard k- $\varepsilon$ model along with the logarithmic wall functions for the turbulent flow range was used. The influence of the mesh size on the accuracy of the fluid flow was studied. Both radial and axial direction temperature distributions have been compared with the experimental data ${ }^{1}$ and the values calculated from a 2DADPF model. A good agreement between the experimental and the predicted values of the pressure drop, temperature distributions and heat transfer coefficient was obtained.
\end{abstract}

Keywords: Packed bed column, Porous media model, Heat transfer, Computational Fluid Dynamics.

\section{INTRODUCTION}

Knowledge of heat transfer characteristics of a packed bed column is important for chemical engineers for controlling the temperature of the packed bed or in determining the performance of processes carried inside the packed beds. Correlations for the heat transfer parameters depend on the velocity profile. Therefore, a fundamental understanding of the fluid flow through the packed beds is required. Conventional experimental measurement techniques applied to measure the fluid flow inside the bed disturb the geometry and flow pattern. Especially at lower Reynolds numbers it is very difficult to obtain a good quality experimental data, since at low gas velocities temperature profiles in the packed bed become very flat. At this point, a particularly useful for the study of heat transfer in the packed bed becomes a Laser Doppler Velocimetry (LDV) used by McGreavy et al. ${ }^{2}$. Stephenson and Stewart ${ }^{3}$ used marker bubbles to measure the radial distribution of flow of a matched refractive index fluid in transparent packed beds. Both studies found an oscillatory radial velocity profile. Kutsovsky et al. ${ }^{4}$ have been used a non-invasive Magnetic Resonance Imaging (MRI) experimental method to obtain local flow patterns in fixed beds. The method has been restricted to low flow rates, $R e<100$ and to fluids which can produce a suitable signal for measurement. The MRI results show that the velocity profile was roughly parabolic with the maximum being near the center of the tube. Negative velocities or reversed flow within the bed were shown ${ }^{4}$. It was also noted that lots of studies have considered heat transfer in the packed bed column ${ }^{5-6}$. These studies reported the experimental correlations for the effective thermal conductivities and wall heat transfer coefficient. The effective heat transfer parameters were derived also based on the two-dimensional axial dispersion plug flow (2DADPF) model ${ }^{1}$. The 2DADPF model was calculated from equation (1):

$$
\mathrm{GC}_{\mathrm{F}} \frac{\partial \mathrm{T}}{\partial \mathrm{x}}=\mathrm{k}_{\mathrm{er}} \frac{1}{\mathrm{r}} \frac{\partial}{\partial \mathrm{r}}\left(\mathrm{r} \frac{\partial \mathrm{T}}{\partial \mathrm{x}}\right)+\mathrm{k}_{\mathrm{eax}} \frac{\partial^{2} \mathrm{~T}}{\partial \mathrm{x}^{2}}
$$

where at the column wall the boundary conditions for the 2DADPF model was given as:

$-\mathrm{k}_{\mathrm{er}} \frac{\partial \mathrm{T}}{\partial \mathrm{r}}=\mathrm{h}_{\mathrm{w}}\left(\mathrm{T}_{\mathrm{w}}-\mathrm{T}\right)$ while at the inlet of the column a uniform temperature distribution was assumed:

$\mathrm{T}=\mathrm{T}_{0}$

Experimental studies of the heat transfer coefficients in the packed bed have been carried by numerous authors $^{7-10}$ and was summarized in Table 1.

Table 1. Results of the experimental studies of the heat transfer in the packed bed

\begin{tabular}{|l|l|c|}
\hline Author & Equation & Equation \\
\hline Calderbank and Pogorski $^{7}$ & $\mathrm{Nu}=4.21 \cdot \mathrm{Re}^{0.365}$ & $(4)$ \\
\hline Yagi and Kunii & \\
\hline Li and Finlayson $^{9}$ & $\mathrm{Nu}=15+0.029 \cdot \mathrm{Re}$ & $(5)$ \\
\hline Demirel et al. $^{10}$ & $\mathrm{Nu}=0.17 \cdot \mathrm{Re}^{0.79}$ & (6) \\
\hline
\end{tabular}

In the last years, there has been an enormous improvement in understanding the heat transfer in a packed bed column achieved by using a Computational Fluid Dynamics (CFD). The earliest CFD fixed bed simulations used two-dimensional modes. The fixed-bed modelling by CFD techniques has been performed by Lattice Boltzmann method (LBM) or based on the finite-volume/ element solution of the continuum equations. The first approach, LBM has been used for the simulations of fixed beds of spheres to analyze isothermal flow fields with chemical reactions ${ }^{11-12}$. The method has not been successful in including heat transfer. Instead of the Lattice Boltzmann method the finite-volume methods have been implemented in the simulation of fixed beds more frequently. The study of particle-to-fluid heat transfer under creeping flow in a $3 \mathrm{D}$ cubic array of spheres ${ }^{13}$ can be considered as one of the earlier applications in this field. The full-bed models with spheres were studied to obtain the heat transfer modeling parameters such as the wall Nusselt numbers ${ }^{14}$ and detailed flow/temperature profiles were obtained ${ }^{15}$ with validation by experimental data $^{16}$. Furthermore, particle-to-fluid mass ${ }^{17}$ and heat transfer were covered with experimental verification ${ }^{18}$. Logtenberg and Dixon ${ }^{19}$ used a commercial finite element code Ansys/Flotran to calculate temperatures at different locations in the bed consisted of eight spheres. The study showed that at the lowest flow rate $(\operatorname{Re}=18)$ the temperature was already almost uniform. At the intermediate Reynolds numbers, the temperature profiles were rapidly changing over the length of two spheres, 
while at $\operatorname{Re}=707$ the temperature profile was hardly developed.

In the presented paper, the porous media model has been used to study heat transfer in the packed bed column in the laminar and turbulent flow regimes. The CFD modelling of heat transfer was carried out in the steady-state for Reynolds number of 8, 187, 291, 328, 378,494 and 556. Based on the comparison between the predicted and experimental values, discussed is the relation between prediction accuracy and mesh density. The investigation covers the impact of the residence time of the flowing gas on the heat rate of air flux in the packed bed column between laminar and turbulent regimes and the effects of the non-uniform heat transfer at the inlet to the packed bed column. Those results are also referred to experimental data ${ }^{20}$. A comparison of the averaged heat transfer coefficient between the predicted and experimental correlations published in the literature was performed. The main purpose of the paper was to work out and validate a numerical modelling method leading to good agreement between the predicted and experimental values of the temperature profiles.

\section{THE METHOD OF MODELLING}

The method of Computational Fluid Dynamics (CFD) was applied to simulate the heat transfer in the packed bed column. The numerical calculations were carried out in both the laminar and turbulent flow regimes. The range of the numerical investigation was summarized in Table 2 and the basic dimensions of the packed bed column - in Table 3. The calculated flow superficial velocities in the packed bed were: $w_{p}=0.023,0.55,0.85$, $0.96,1.1,1.44$ and $1.62\left[\mathrm{~ms}^{-1}\right]$, respectively for the given Reynolds numbers.

Table 2. Range of the CFD studies

\begin{tabular}{|l|c|c|}
\hline Medium & $\begin{array}{c}\text { Laminar flow } \\
\text { regime }\end{array}$ & Turbulent flow regime \\
\hline $\begin{array}{l}\text { Air - packed } \\
\text { bed }\end{array}$ & $\operatorname{Re}=8$ & $\operatorname{Re}=187,291,328,378$, \\
494,556
\end{tabular}

Table 3. Basic dimensions of the packed bed column similar to the experimental setup of Wen and Ding ${ }^{1}$

\begin{tabular}{|l|c|}
\hline Dimension & Packed bed column \\
\hline column length, $\mathrm{m}$ & 1.1 \\
\hline column diameter, $\mathrm{m}$ & 0.041 \\
\hline glass balls diameter, $\mathrm{m}$ & 0.005 \\
\hline
\end{tabular}

The CFD model was based on an experimental setup of Wen and Ding'. Glass balls were packed into the column in a random manner and compressed air was passed through the bed from the inlet at the bottom of the column toward the outlet at the top. Wen and Ding ${ }^{1}$ measured an axial temperature profile in the column centre by thermocouples located at seven axial positions of $30,188,379,579,764,964$ and 1062 [mm] from the inlet. The second kit of five thermocouples was located in two axial positions of 579 and $764[\mathrm{~mm}]$ from the inlet and was used to measure radial temperature profiles.

The ANSYS $12.1^{21}$ was used to the heat transfer simulations in the packed bed column. The Gambit 2.0 preprocessor was employed to generate the applied numerical grids: three hexahedral grids of different nu- merical density: $31178-(31 \mathrm{k}), 70125-(70 \mathrm{k})$ and 126 644 - (126k) computational cells. Labels were used to distinguish the grid sizes. The quality of grids was tested by an EquiAngleSkew parameter.

The standard Navier-Stokes equations (Eq. (8) with Eq. (9)) along with the energy transport equation (Eq. (10)) were solved in laminar flow regime, whereas the standard Reynolds averaged Navier-Stokes (RANS) equations (Eq. (11)) with the continuity (Eq. (12)) and energy transport (Eq. (13)) were solved in the turbulent heat transfer modelling.

$\nabla \cdot(\rho \overline{\mathrm{uu}})=\nabla\left(\mu\left[\left(\nabla \overline{\mathrm{u}}+\nabla \overline{\mathrm{u}}^{\mathrm{T}}\right)-\frac{2}{3} \nabla \overline{\mathrm{u}} \overline{\mathrm{I}}\right]\right)+\rho \overline{\mathrm{g}}+\overline{\mathrm{F}}-\nabla \mathrm{p}$

$\nabla \cdot(\rho \overline{\mathrm{u}})=0$

$\nabla \cdot\left(\rho c_{p} \overline{\mathrm{u}} \overline{\mathrm{T}}\right)=\nabla \cdot(\lambda \nabla \overline{\mathrm{T}})$

$\nabla \cdot(\rho \overline{\mathrm{uu}})=\nabla\left(\left(\mu+\mu_{t}\right)\left[\left(\nabla \overline{\mathrm{u}}+\nabla \overline{\mathrm{u}}^{\mathrm{T}}\right)-\frac{2}{3} \nabla \overline{\mathrm{u}} \overline{\mathrm{I}}\right]\right)+\rho \overline{\mathrm{g}}+\overline{\mathrm{F}}-\nabla \mathrm{p}$

$\nabla \cdot(\rho \overline{\mathrm{u}})=0$

$\nabla \cdot\left(\rho c_{\mathrm{p}} \overline{\mathrm{u}} \overline{\mathrm{T}}\right)=\nabla \cdot\left(\left(\lambda+\lambda_{\mathrm{t}}\right) \bar{\nabla} \overline{\mathrm{T}}\right)$

The terms on the left-hand side of Eqs. (8), (10), (11) and (13) represent the rates of addition by convection of the momentum, temperature, mean momentum and mean temperature, respectively. The first term on the right-hand side of these equations describes the input of the molecular transport. The quantity, $\bar{F}$ stands for the external force exerted on the fluid and to simulate the flow inside the porous structure for a given $i^{\text {th }}$ flow direction was given by equation (14) called a Porous Media Model' ${ }^{21}$ :

$\mathrm{F}_{\mathrm{i}}=-\left(\frac{\mu}{\alpha} \mathrm{u}_{\mathrm{i}}+\mathrm{C}_{2} \frac{1}{2} \rho \mathrm{w}_{\mathrm{p}} \mathrm{u}_{\mathrm{i}}\right)$

The heat transfer model in Porous Media Model assumed the local thermal equilibrium between the fluid and solid phase. The packed bed permeability, $\alpha$ and the inertial resistance factor, $C_{2}$, were calculated from the Eqs. (15) and $(16)^{21}$, respectively:

$$
\begin{gathered}
\alpha=\frac{\mathrm{d}_{\mathrm{z}}^{2}}{150} \frac{\varepsilon_{\mathrm{b}}^{3}}{\left(1-\varepsilon_{\mathrm{b}}\right)^{2}} \\
\mathrm{C}_{2}=\frac{3.5}{\mathrm{~d}_{\mathrm{z}}} \frac{\left(1-\varepsilon_{\mathrm{b}}\right)}{\varepsilon_{\mathrm{b}}^{3}}
\end{gathered}
$$

In the laminar flow modelling inertial losses may be omitted and the factor $C_{2}$ is not required.

In order to close the equation set (of Eqs. (11) and (12)), the standard $k-\varepsilon$ turbulence mode ${ }^{21}$ was used (Eqs. (17) and (18)):

$$
\begin{aligned}
& \frac{\partial\left(\rho \overline{\mathrm{u}}_{\mathrm{i}} \mathrm{k}\right)}{\partial \mathrm{x}_{\mathrm{i}}}=\frac{\partial}{\partial \mathrm{x}_{\mathrm{i}}}\left[\left(\mu+\frac{\mu_{\mathrm{t}}}{\sigma_{\mathrm{k}}}\right) \frac{\partial \mathrm{k}}{\partial \mathrm{x}_{\mathrm{i}}}\right]-\rho \overline{\mathrm{u}_{\mathrm{i}} \mathrm{u}_{\mathrm{j}}^{\prime}} \frac{\partial \overline{\mathrm{u}}_{\mathrm{j}}}{\partial \mathrm{x}_{\mathrm{i}}}-\rho \varepsilon \\
& \frac{\partial\left(\rho \overline{\mathrm{u}}_{\mathrm{i}} \varepsilon\right)}{\partial \mathrm{x}_{\mathrm{i}}}=\frac{\partial}{\partial \mathrm{x}_{\mathrm{i}}}\left[\left(\mu+\frac{\mu_{\mathrm{t}}}{\sigma_{\varepsilon}}\right) \frac{\partial \varepsilon}{\partial \mathrm{x}_{\mathrm{i}}}\right]+\mathrm{C}_{1 \mathrm{\varepsilon}} \frac{\varepsilon}{\mathrm{k}}\left[-\rho \overline{\mathrm{u}_{\mathrm{i}}^{\prime} \mathrm{u}_{\mathrm{j}}^{\prime}} \frac{\partial \overline{\mathrm{u}}_{\mathrm{j}}}{\partial \mathrm{x}_{\mathrm{i}}}\right]-\mathrm{C}_{2 \varepsilon} \rho \frac{\varepsilon^{2}}{\mathrm{k}}
\end{aligned}
$$

where $k$ is the turbulent kinetic energy and $\varepsilon$ its dissipation rate. The turbulent eddy viscosity, $\mu_{t}$, was specified as follows: 


$$
\mu_{\mathrm{t}}=\rho \mathrm{C}_{\mu} \frac{\mathrm{k}^{2}}{\varepsilon}
$$

Eqs. (17) and (18) contain adjustable constants: $C_{1 \varepsilon}=$ 1.4, $C_{2 \varepsilon}=1.92, C_{\mu}=0.09, \sigma_{k}=1.0, \sigma_{e}=1.3$ and $\operatorname{Pr}_{\mathrm{t}}=$ 0.85 . The boundary flow at the packed bed column wall was described by the standard logarithmic wall functions. The numerical solution of these equation sets allow to predict both the local velocities and temperatures.

All the boundary conditions for heat transfer were defined in the ANSYS code. The gas temperature at the inlet was assumed $293[\mathrm{~K}]$. The temperature of the column wall was set to $373 \mathrm{~K}$ and this was called the heating wall. The gas properties based on the ANSYS database and are presented in Table 4.

Table 4. The gas properties at the temperature $293 \mathrm{~K}$

\begin{tabular}{|l|c|}
\hline Parameter & Value \\
\hline Density & $1.225 \mathrm{kgm}^{-3}$ \\
\hline Viscosity & $1.7894 \cdot 10^{-5} \mathrm{kgm}^{-1} \mathrm{~s}^{-1}$ \\
\hline Heat capacity & $1006.43 \mathrm{Jkg}^{-1} \mathrm{~K}^{-1}$ \\
\hline Heat conductivity coefficient & $0.0242 \mathrm{Wm}^{-1} \mathrm{~K}^{-1}$ \\
\hline
\end{tabular}

Physical properties of the column were assessed with the use of an ANSYS database: steel density, $\rho_{s t}=8030$ $\left[\mathrm{kgm}^{-3}\right]$; steel heat capacity, $c_{p s t}=502.48\left[\mathrm{Jkg}^{-1} \mathrm{~K}^{-1}\right]$ and steel heat conductivity coefficient, $k_{s t}=16.27\left[\mathrm{Wm}^{-1} \mathrm{~K}^{-1}\right]$. The boric-silica particles of diameter $5[\mathrm{~mm}]$ stated the real column packing of the bed ${ }^{\mathbf{1}}$. Characteristic of simulated sphere packing is presented in Table 5.

Table 5. Characteristic of simulated sphere packing

\begin{tabular}{|l|l|}
\hline Parameter & Value \\
\hline Particle diameter & $5 \cdot 10^{-3} \mathrm{~m}$ \\
\hline Density & $2590 \mathrm{kgm}^{-3}$ \\
\hline Heat capacity & $780 \mathrm{Jkg}^{-1} \mathrm{~K}^{-1}$ \\
\hline Heat conductivity coefficient & $0.9656 \mathrm{Wm}^{-1} \mathrm{~K}^{-1}$ \\
\hline Mean void fraction & 0.416 \\
\hline Packed bed permeability & $3.5 \cdot 10^{-7} \mathrm{~m}^{2}$ \\
\hline Inertial resistance factor & $5678.46 \mathrm{~m}^{-1}$ \\
\hline
\end{tabular}

Density, heat capacity and heat conductivity coefficient for particles were taken from ${ }^{22}$, while the remaining parameters: bed permeability, $\alpha$, and inertial resistance factor, $C_{2}$, were assessed with the use of equation (15) and (16), respectively. While the mean void fraction, $\varepsilon_{b}$, can be calculated from equation Jeshar's ${ }^{1}$ (Eq. (20)):

$\varepsilon_{\mathrm{b}}=0.375+0.34 \frac{\mathrm{d}_{\mathrm{z}}}{\mathrm{D}}$

Validation of CFD results against experimental data is an essential part of research and will be established on pressure drop. The pressure loss during flow through the packed bed is given by the sum of two terms: a viscous energy loss, proportional to the fluid velocity and an inertial loss term, proportional to the velocity squared. Ergun $^{\mathbf{2 3}}$ defined empirical parameters occurred by these terms as following:

$\frac{\Delta \mathrm{P}}{\mathrm{L}}=\frac{150 \mu\left(1-\varepsilon_{\mathrm{b}}\right)^{2}}{\mathrm{~d}_{\mathrm{z}}^{2} \varepsilon_{\mathrm{b}}^{3}} \mathrm{u}+\frac{1.75 \rho\left(1-\varepsilon_{\mathrm{b}}\right)}{\varphi \mathrm{d}_{\mathrm{z}} \varepsilon_{\mathrm{b}}^{3}} \mathrm{u}^{2}$

While packed beds are composed particles that vary much in shape from sphere, the corrections to the Ergun equation should be applied. Macdonald et al. ${ }^{24}$ have proposed the use of modified coefficients of 180 and
1.80 as more acceptable for particles of arbitrary shape instead of two constants 150 and 1.75 in equations (21). Ergun equation (21) applies to both the laminar and the turbulent flow regimes. For the laminar flow the inertial loss term (the second term on the right-hand side of equation (21)) may be omitted and the pressure drop formulation simplifies itself.

The heat transfer rate, $\dot{\mathrm{q}}$, averaged over the whole heating surface was obtained as a result of the heat transfer simulations. Then the averaged heat transfer coefficient, $\alpha_{\mathrm{q}}$, was calculated from equation (22), where is the averaged temperature drop between the gas and the heating wall calculated from equation (23):

$$
\begin{aligned}
& \alpha_{\mathrm{q}}=\frac{\dot{\mathrm{q}}}{\Delta \mathrm{T}_{\alpha}} \\
& \Delta \mathrm{T}_{\alpha}=\frac{\left(\mathrm{T}_{\mathrm{w}}-\mathrm{T}_{0}\right)+\left(\mathrm{T}_{\mathrm{w}}-\mathrm{T}_{\text {outlet }}\right)}{2}
\end{aligned}
$$

The predicted values of the averaged heat transfer coefficient, $\alpha_{\mathrm{q}}$, from equation (22) were used for comparison with the literature experimental data ${ }^{\mathbf{7 , 9 , 1 0}}$.

The segregated solver was used for the numerical simulations. The flow was regarded as isothermal and constant air physical properties were input. Constant values of density, viscosity, specific heat and thermal conductivity were adopted, respectively. A velocity inlet at the flow inlet of the column was used. The flow exit boundary was defined as an atmospheric pressure outlet. At the central part of every grid created a volumetric zone of numerical cells was allotted for the porous medium conditions to be imposed. For the porous medium fluid zone superficial velocity formulation was chosen to be solved and additional quantities were declared void fraction and packed bed permeability for each of the space coordinates. Simulations were carried out in the steady state. In the laminar flow regime, the first step was to determine the flow field and then the energy equation was solved. In the turbulent flow regime, the initial computations for the pseudo-laminar flow with the turbulence model turned off were carried out. Then, the turbulence model and the near-wall region model were used to simulating of the turbulent velocity field. Finally, the energy equation was solved. The iterations were carried out as long as the standardized sum of residuals fell below at least $1.10^{-5}$ and the residual plot showed a plateau for at least 100 last iterations.

\section{RESULTS AND DISCUSSION}

The pressure drop through the packed bed for seven Reynolds numbers of 8, 187, 291, 328, 378, 494 and 556 was obtained. The comparison was made between experimental results ${ }^{1}$, Ergun ${ }^{23}$ correlation (21) and CFD. Results which are shown in Figure 1 present good qualitative agreements between CFD and experimental results ${ }^{1}$, the relative error was $12.3 \%$. While the agreement between CFD and Ergun model (21) was better and the average error was $1.2 \%$. Wen and Ding ${ }^{1}$ results have varied from both the CFD results and Ergun model values. The main cause of the discrepancy implies non-uniform gas density and viscosity distributions in comparison to the assumed constants values. Another possible reason of the discrepancy is that the void fraction is based on the 
constant mean value calculated from the equation (20), which is untrue as shown in Mueller ${ }^{25}$. The density of the numerical mesh has no significant influence on the CFD results. The pressure drop values obtained from the CFD modelling using meshes $31 \mathrm{k}, 70 \mathrm{k}$ and $126 \mathrm{k}$ were close to each other.

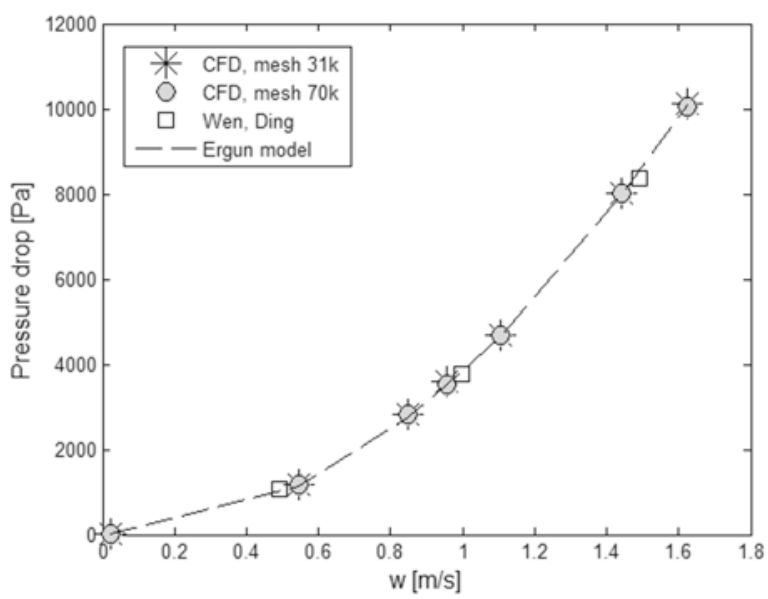

Figure 1. Pressure drop $[\mathrm{Pa}]$ variations with velocity

The analysis of temperature profiles in the column did not reveal the relevant influence of the mesh size on the gas stream temperature values as shown in Figure 2. A comparison between the steady-state temperature distributions in the packed bed column at Reynolds number, $R e=328$ at $h=0.579[\mathrm{~m}]$ indicated that the temperature profiles are nearly identical for chosen mesh sizes.

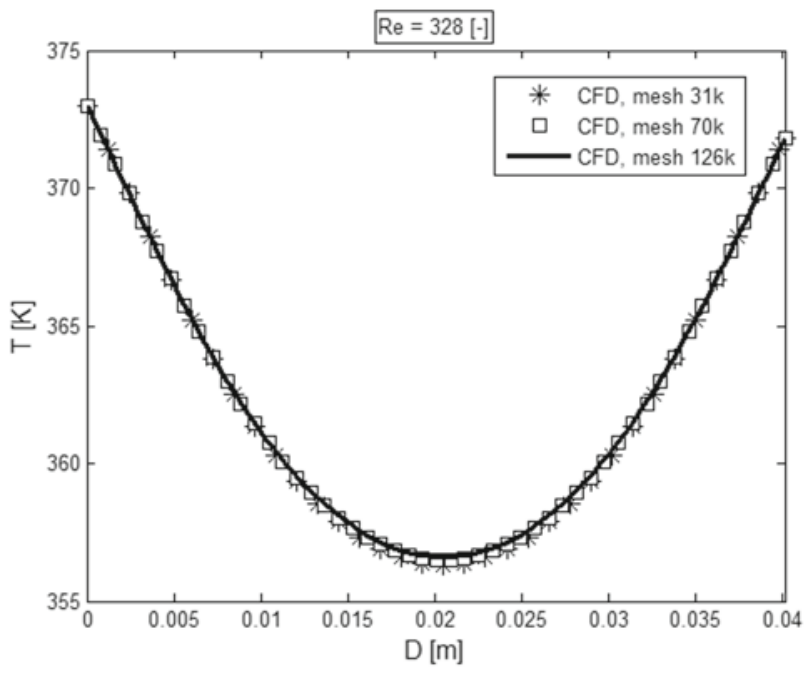

Figure 2. Temperature distributions [K] obtained for 0.579 [m] from the inlet to the packed bed column at $R e=328$ for three mesh sizes

In Figure 3 the contours of temperature magnitude inside the packed bed column at laminar and turbulent regimes ( $R e=8$ and 556, respectively) show the column parts of steady gas stream temperature. It shows that the gas temperature inside the column at a specific position is constant and equal to the wall temperature. The gas stream temperature in the packed bed column establishes sooner for lower gas velocity. This trend is also well predicted by the CFD simulations as shown in Figure 4. The gas stream temperature at laminar flow condition at $h=5[\mathrm{~cm}]$ is only slightly non-uniform, while at $h=10[\mathrm{~cm}]$ from the inlet to the packed bed column geometry is constant and equal to $373[\mathrm{~K}]$. A comparison between Figure $4 \mathrm{a}$ and $4 \mathrm{~b}$ indicates that the non-uniformity of the temperature distribution at the same column heights, $h=5$ and $10[\mathrm{~cm}]$, is clearly visible at turbulent regime, where $R e=556$. There is a significant temperature drop at the middle of the column (293 [K]) and the gas stream temperature increases towards the column wall with a steeper increase near the wall to $373[\mathrm{~K}]$.

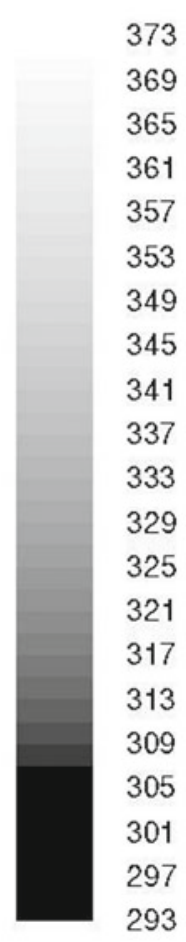

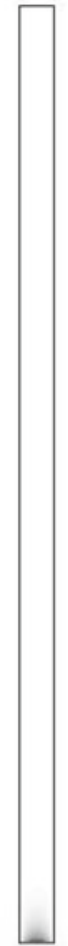

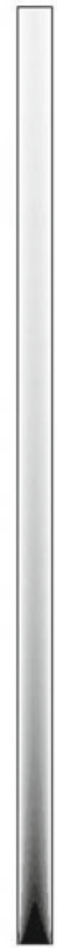

b)
Figure 3. Contour of temperature values $[\mathrm{K}]$ in the crosssection of the packed bed column: a) laminar flow, $R e=8, \mathrm{~b})$ turbulent flow, $R e=556$

The large discrepancy of the heat rate of air flux in the packed bed column was noticed between laminar and turbulent regimes (Figure 3). This is mainly due to various values of the residence time of the flowing gas inside the bed. The mean residence time of air flux at laminar flow was 24,44 [s] $(R e=8)$, while at turbulent flow 0,34 [s] $(R e=556)$. This means that gas flows through the packed bed column 72 times longer at laminar flow, hence the profiles of temperature at $h=5$ and $10[\mathrm{~cm}]$ from the inlet to the packed bed column were uniform (Figure 4a) as opposed to non-uniform temperature distribution at turbulent flow (Figure $4 b$ ).

A number of numerous studies of the heat transfer at the packed bed column determined the temperature distributions only at the outlet of the bed ${ }^{\mathbf{2 0 , 2 6 , 2 7}}$. However, details temperature profiles in the interior of packed beds are insufficiently identified. Figure 5 shows the gas stream temperature distributions along a column axis at different Reynolds number values. The overall axial pattern shows a typical temperature profile for flow through the packed bed column. The axial gas stream temperature at the inlet was equaled to $293[\mathrm{~K}]$ and increases as the axial distance to the column wall grows. In all the cases considered at the axial position $H$ lower than $0.2[\mathrm{~m}]$, the temperature increases slowly, then 

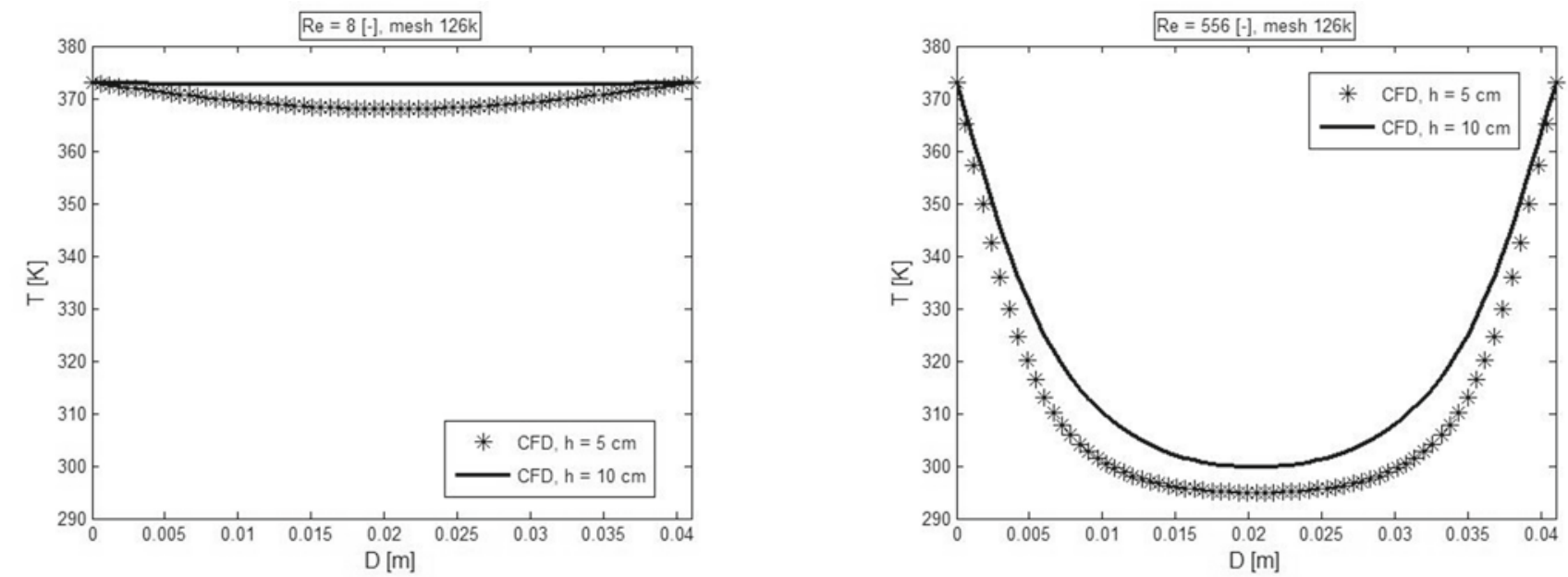

Figure 4. Profiles of temperature at $h=5$ and $10[\mathrm{~cm}]$ from the inlet to the packed bed column: a) laminar flow, $R e=8$, b) turbulent flow, $R e=556$

rapidly increases and finally again slowly increases again at $H$ greater than $0.6[\mathrm{~m}]$. The temperature approaches a steady-state faster for lower Reynolds number. This trend can be noticed both for the experimental data ${ }^{\mathbf{1}}$ and CFD results. The rate of temperature increase drops at the inlet (at the axial position $H$ below $0.2[\mathrm{~m}]$ ) due to the contact resistance at the wall and the non-uniform velocity distribution of the flowing gas inside the bed. The maximum superficial gas velocity is at the axis of the bed and drops as the distance to the column wall decreases. The non-uniform velocity distribution implies the non-uniform heat transfer. The heat transfer is a function of the axial position and depends on the heating length. Dixon and van Dongeren ${ }^{20}$ suggest that the effective thermal conductivities and the wall heat transfer coefficient decrease with increasing heating length and approach constant values at 400 [mm] after which the flow is fully developed. Dixon and van Dongeren ${ }^{20}$ found that the length-dependence effect could be eliminated by using the non-heating calming zone to obtain an artificially fully developed flow. Differences between the temperature profiles obtained from the CFD modelling and experimental measurements ${ }^{1}$ are narrow. Simulated results show the best agreement with the experimental data $^{1}$ at the inlet to the packed bed column and with increasing the column height the temperature differences increase. Simulated results show reasonably good qualitative as well as quantitative agreement with experimental data at $R e=291,328$ and 556 (see Figure 5, where relative errors were 1.6 and 1.9 [\%], respectively). The worst agreement was obtained at the Reynolds number, $R e=187$ (3.6 [\%]), while at $R e=494$ relative error was equaled to 2.3 [\%]. At $R e=291,328$ and 556 the CFD curves of the axial temperature profile for different mesh sizes overlapped.

Figure 6 shows the predicted from 2DADPF model and CFD simulations axial temperature distributions at the column centre for $R e=328$ and 378 together with measurements ${ }^{1}$. The predicted from 2DADPF model at $R e=328$ axial temperature distribution agrees very well with the CFD results. While the CFD prediction at $R e=378$ agrees reasonably well with measurements ${ }^{1}$ with slight overprediction in the lower part of the column and underprediction in the upper part of the column.

Figure 7 shows a comparison of the predicted 2DADPF and CFD models radial temperature distributions with the measurements ${ }^{1}$ at two axial positions of $h=0.594$ and $0.764[\mathrm{~m}]$ for $R e=328$ and 378 .

The CFD results at chosen axial positions $(h=0.579$ and $0.764[\mathrm{~m}]$ ) agree well with the 2DADPF predictions for $R e=328$ with only slight overprediction in the close distance to the wall column. While the agreement between the CFD results with the measurements ${ }^{1}$ for $R e=378$ was rather poor. The discrepancies between the predictions and measurements described above may be due to the 2DADPF and CFD models assume a uniform porosity distribution in packed bed column and the first model neglects the radial flow distributions. Experimental observations ${ }^{28}$ strongly indicate that the large voidage at the wall region exerts a significant effect on the flow, hence the heat transfer behaviour. The CFD radial temperature distributions at $h=0.579$ [m] reflected that tendency, where in Figure 7a large temperature drop occur at the wall region.

In the next step of analysis, the predicted CFD values of the averaged heat transfer coefficient were compared with the experimental values calculated from correlations published in the literature ${ }^{\mathbf{7 , 9 , 1 0}}$. In the case of heat transfer to gas in the packed bed column at $R e=8$, the difference between the predicted and calculated (Eq. (6)) values of the averaged heat transfer coefficient, $\alpha_{\mathrm{q}}$, was equal to 26.2 [\%] for the $126 \mathrm{k}$ grid cells. The predicted values of $\alpha_{\mathrm{q}}$ were higher than the experimental values obtained from equations (4) and (7) by about 65 [\%] and 43 [\%], respectively. These results were obtained assuming constant fluid properties in the numerical simulations. The discrepancies between the CFD and experimental values of the averaged heat transfer coefficient can be lower when the properties will be assumed temperature dependent.

The relative differences between the CFD values and those calculated from Eqs. (4), (6) and (7) of the averaged heat transfer coefficient, $\alpha_{\mathrm{q}}$, in the turbulent flow regime are presented in Table 6.

The discrepancy was significantly lower when the turbulent flow regime was considered. The biggest discrepancies between the predicted and experimental values of $\alpha_{\mathrm{q}}$ were obtained for calculated from equation (6) proposed by $\mathrm{Li}$ and Finlayson'. The best agreement of $\alpha_{\mathrm{q}}$ was obtained between the predicted and calculated 

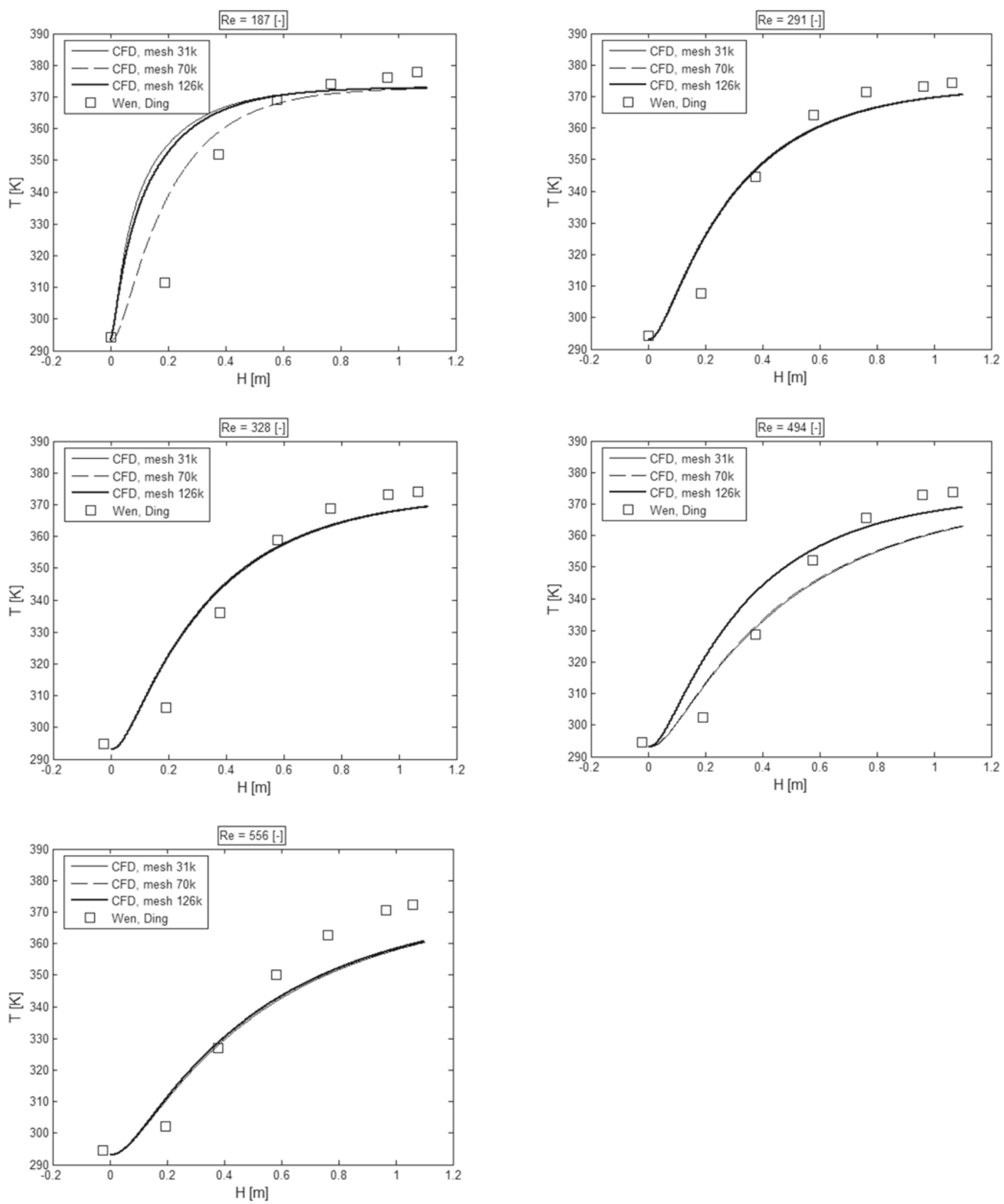

Figure 5. Comparison between predicted axial temperature distributions using the CFD results with measurements ${ }^{1}$ at $R e=187$; 291; 328; 494 and 556

values from equation (7) proposed by Demirel et al. ${ }^{\mathbf{1 0}}$. The predicted values of heat transfer coefficient were close to the experimental ones. The effect of the grid density on the value of $\alpha_{\mathrm{q}}$ was not significant for the packed bed column.

\section{CONCLUSIONS}

Results of the standard Navier-Stokes and the Reynolds averaged Navier-Stokes approaches of the gas flow with the heat transfer through the packed bed column have been presented in the laminar and turbulent flow regimes, respectively. The pressure drop has been compared with the values calculated from Erqun equation (21), the relative error was in approximation of 1.2 [\%]. The temperature profiles in the laminar flow regime were uniform, while the increase in the Reynolds number to the turbulent flow regime carried out to non-uniform temperature profiles in range $293-373$ [K] at the column height $10[\mathrm{~cm}]$. A direct qualitative and quantitative 
Table 6. Relative differences between predicted (mesh 126k) and experimental values ${ }^{\mathbf{7 , 9}, 10}$ of the heat transfer coefficient, $\alpha_{\mathrm{q}}$

\begin{tabular}{|l|c|c|c|c|c|c|}
\hline Reynolds number, Re & 187 & 291 & 328 & 378 & 494 & 556 \\
\hline Relative difference between $\alpha_{q}$ (CFD) and $\alpha_{q}$ (Eq.(4)) [\%] & 23.6 & 13.4 & 8.3 & 2.9 & 18.3 & -10.5 \\
\hline Relative difference between $\alpha_{q}$ (CFD) and $\alpha_{q}$ (Eq.(6)) [\%] & 16.5 & 21.3 & 20.9 & 20.8 & 40.7 & 23.7 \\
\hline Relative difference between $\alpha_{q}$ (CFD) and $\alpha_{q}$ (Eq.(7)) [\%] & -4.6 & -5.5 & -8.1 & -10.4 & 13.6 & -13.2 \\
\hline
\end{tabular}

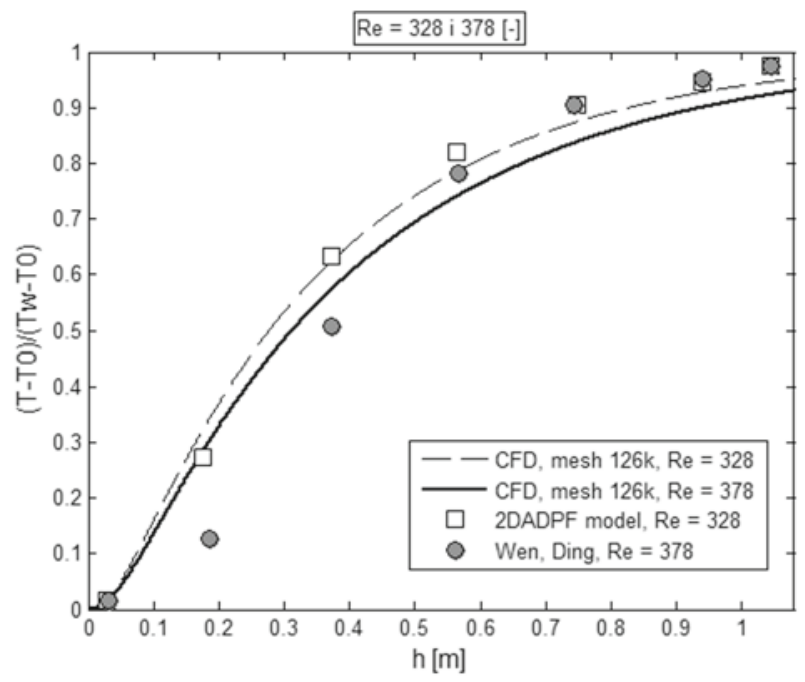

Figure 6. Comparison of CFD predicted axial temperature distributions with measurement data ${ }^{\mathbf{1}}$ and calculated values from $2 \mathrm{DADPF}$ model at $R e=328$ and 378

a)

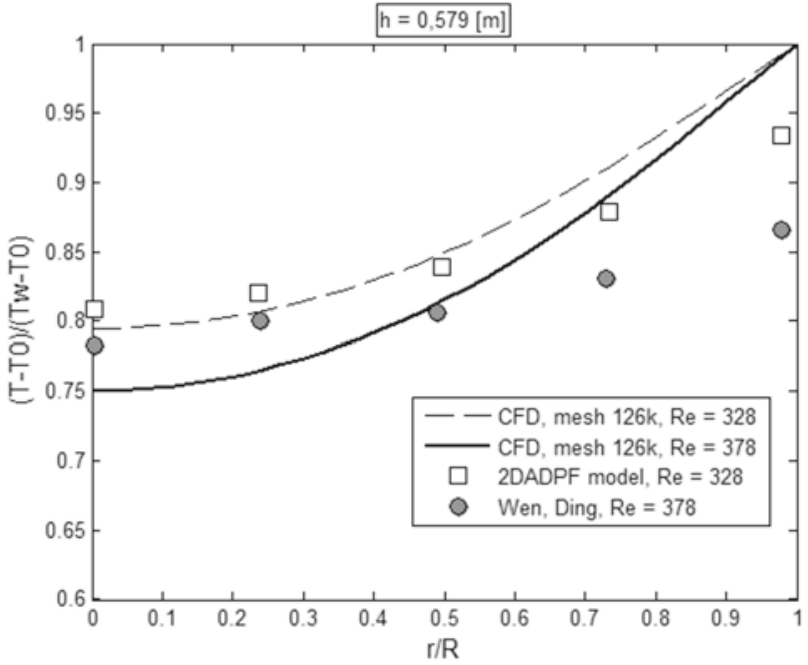

b)

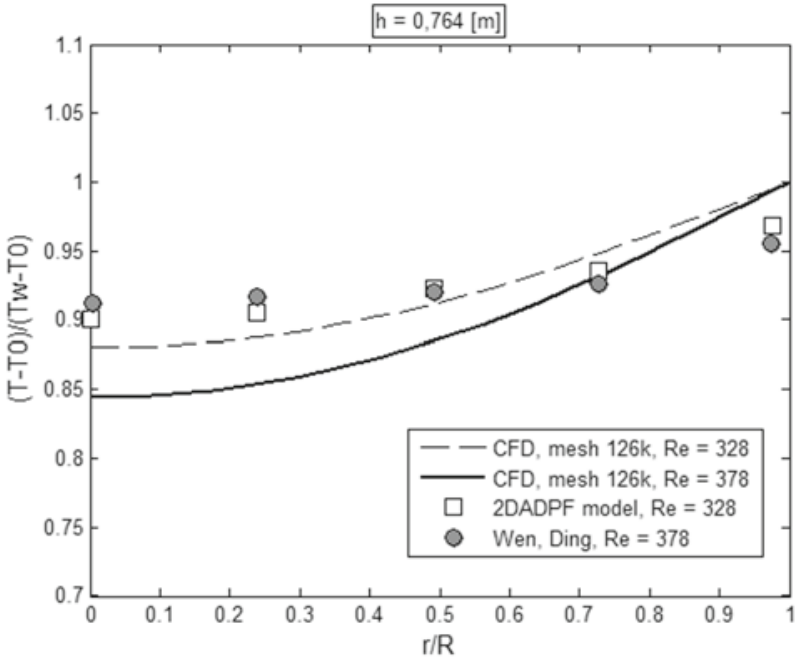

Figure 7. Comparison of CFD result at $h=0.579$ (a) and $0.764[\mathrm{~m}](\mathrm{b})$ with measurement data $^{1}$ and calculated 2DADPF model for $R e=328$ and 378 comparisons between the axial temperature profiles of Wen and Ding experiments ${ }^{1}$ and CFD simulations have shown that the CFD results agreed reasonably well with the experimental values ${ }^{1}$. The agreement between the CFD radial temperature distributions with the prediction 2DADPF model and experiments ${ }^{1}$ was worsen probably due to assumption of uniform gas density and viscosity distributions, but mostly due to length-dependent behaviour of the heat transfer parameters. The predicted values of the averaged heat transfer coefficient, $\alpha_{\mathrm{q}}$, were close to the experimental in the turbulent flow regimes. In the laminar flow regime the differences between the CFD and calculated from equations (4), (6) or (7) values of $\alpha_{q}$ were bigger than in the turbulent flow regime. The smallest discrepancy between the modelling and $\mathrm{Li} \&$ Finlayson ${ }^{9}$ of the heat transfer coefficient of 26.2 [\%] was obtained in the laminar flow regime. In the turbulent flow regime the best agreement of the averaged heat transfer coefficient between the CFD value and calculated from equation (4) was obtained (2.9 [\%]) for $\mathrm{Re}=378$. However, for the whole range of the Reynolds numbers in the turbulent flow regime the mean values of the heat transfer coefficient agreed well with the values from equation (7). It can be concluded that better agreement between the numerical and experimental results can be obtained if the density, viscosity, specific heat and conductivity parameters will be described by the models of incompressible ideal gas, power law and kinetic theory, respectively as well as if the non-heating calming regime at the inlet to the packed bed column will be enough long to obtain fully developed flow. Therefore, the presented numerical approaches can be used as methods of pre-evaluation of the performance of temperature profiles inside the porous media.

\section{NOMENCLATURE}

$\mathrm{c}_{\mathrm{p}} \quad$ heat capacity $\left[\mathrm{Jkg}^{-1} \mathrm{~K}^{-1}\right]$

$\stackrel{\mathrm{p}_{\mathrm{F}}}{\mathrm{C}_{2}} \quad$ gas phase specific heat $\left[\mathrm{Jkg}^{-1} \mathrm{~K}^{-1}\right]$

$\mathrm{C}_{2} \quad$ inertial resistance factor $\left[\mathrm{m}^{-1}\right]$

$\mathrm{C}_{1 \varepsilon}, \mathrm{C}_{2 \varepsilon}, \mathrm{C}_{\mu}$ model constants [-]

$\mathrm{d}_{\mathrm{z}} \quad$ particle diameter $[\mathrm{m}]$

$\bar{F}, \mathrm{~F}_{\mathrm{i}} \quad$ external body forces component $[\mathrm{N}]$

$\mathrm{G}$ mass flow rate $\left[\mathrm{kgm}^{-2} \mathrm{~s}^{-1}\right]$

$\bar{g} \quad$ gravitational body force $\left[\mathrm{ms}^{-2}\right]$

$\mathrm{h}$ axial direction [m]

$\mathrm{H} \quad$ column height [m]

$\mathrm{h}_{\mathrm{w}} \quad$ apparent wall heat transfer coefficient $\left[\mathrm{Wm}^{-2} \mathrm{~K}^{-1}\right]$

$\mathrm{i} \quad \mathrm{j}$-th spatial direction $[-]$

$\bar{I} \quad$ unit tensor

$\mathrm{k} \quad$ turbulent kinetic energy $\left[\mathrm{m}^{2} \mathrm{~s}^{-2}\right]$

$\mathrm{k}_{\mathrm{er}} \quad$ effective radial thermal conductivity

$\left[\mathrm{Wm}^{-1} \mathrm{~K}^{-1}\right]$

$\mathrm{k}_{\text {eax }} \quad$ effective axial thermal conductivity

$\left[\mathrm{Wm}^{-1} \mathrm{~K}^{-1}\right]$ 
L length of fixed bed [m]

$\mathrm{p} \quad$ static pressure $\left[\mathrm{Nm}^{-2}\right]$

$\mathrm{Pr}_{\mathrm{t}} \quad$ turbulent Prandtl number [-]

$\mathrm{r}$ radial coordinate $[\mathrm{m}]$

$\mathrm{R} \quad$ tube radius [m]

Re Reynolds number [-]

$\dot{\mathrm{q}} \quad$ heat transfer rate $\left[\mathrm{Wm}^{-2}\right]$

$\mathrm{T}$ temperature $[\mathrm{K}]$

$\mathrm{T}_{\mathrm{w}} \quad$ wall temperature [K]

$\mathrm{T}_{0} \quad$ inlet temperature [K]

$\mathrm{T}_{\text {outlet }} \quad$ outlet temperature $[\mathrm{K}]$

$\mathrm{u} \quad$ velocity $\left[\mathrm{ms}^{-1}\right]$

$\mathrm{w}_{\mathrm{p}} \quad$ apparent velocity calculated on empty column $\left[\mathrm{ms}^{-1}\right]$

$\mathrm{x}, \mathrm{y}, \mathrm{z} \quad$ spatial coordinates [m]

\section{Greek symbols}

$\alpha$

$\alpha_{\mathrm{q}}$

$\delta$

$\varepsilon$

$\varepsilon_{\mathrm{b}}$

$\gamma$

$\lambda$

$\lambda_{\mathrm{t}}$

$\mu$

$\mu_{\mathrm{t}}$

$\rho$

$\sigma_{\mathrm{k}}, \sigma_{\varepsilon}$

$\Delta \mathrm{P}$

$\Delta \mathrm{T}_{\alpha}$

packed bed permeability $\left[\mathrm{m}^{2}\right]$

averaged heat transfer coefficient

$\left[\mathrm{Wm}^{-2} \mathrm{~K}^{-1}\right]$

relative error [\%]

dissipation rate of kinetic turbulence

energy $\left[\mathrm{m}^{2} \mathrm{~s}^{-3}\right]$

void fraction $\left[\mathrm{m}^{3}{ }_{\text {voids }} \mathrm{m}^{-3}\right.$ packedbed $]$

porosity of the media $\left[\mathrm{m}^{3}\right.$ fluid $\mathrm{m}^{-3}$ total $]$

laminar thermal conductivity $\left[\mathrm{Wm}^{-1} \mathrm{~K}^{-1}\right]$

turbulent thermal conductivity $\left[\mathrm{Wm}^{-1} \mathrm{~K}^{-1}\right]$

viscosity [Pas]

turbulent eddy viscosity [Pas]

fluid density $\left[\mathrm{kgm}^{-3}\right]$

equivalent parameters for Prandtl number

for $\mathrm{k}$ and $\varepsilon[-]$

pressure loss $\left[\mathrm{Nm}^{-2}\right]$

\section{LITERATURE CITED}

1. Wen, D. \& Ding, Y. (2006). Heat transfer of gas flow through a packed bed. Chem. Eng. Sci. 61, 3532-3542. DOI: 10.1016/j.ces.2005.12.027.

2. McGreavy, C., Foumeny, E.A. \& Javed, K.H. (1986). Characterization of transport properties for fixed bed in terms of local bed structure and flow distribution. Chem. Eng. Sci. 41, 787-797. DOI: 10.1016/0009-2509(86)87159-7.

3. Stephenson, J.L. \& Stewart, W.E. (1986). Optical measurements of porosity and fluid motion in packed beds. Chem. Eng. Sci. 41, 2161-2170. DOI: 10.1016/0009-2509(86)87132-9.

4. Kutsovsky, Y.E., Scriven, L.E., \& Davis, H.T. (1196). NMR imaging of velocity profiles and velocity distribution in bead packs. Phys. Fluids. 8, 863-871. DOI: 10.1063/1.868867.

5. Bey, O. \& Eigenberger, G. (2001). Gas flow and heat transfer through catalyst filled tubes. Int. J. Therm. Sci. 40, 152-164. DOI: 10.1016/S1290-0729(00)01204-7.

6. Collier, A., Hayhurst, A., Richardson, J. \& Scott S. (2004). The heat transfer coefficient between particle and a bed (packed or fluidised) of much larger particles. Chem. Eng. Sci. 59, 4613-4620. DOI: 10.1016/j.ces.2004.07.029.

7. Calderbank, P. \& Pogorski, L. (1957). Heat transfer in packed beds. Trans. Inst. Chem. Eng. 35, 195-207.

8. Yagi, S. \& Kunii, D. (1960). Studies on heat transfer near wall surfaces in packed beds. J. Amer. Inst. Chem. Eng. 1, 97-104.

9. Li, C. \& Finlayson, B. (1977). Velocity, temperature and conversion profiles in fixed bed catalytic reactors. Chem. Eng. Sci. 32, 853-861. DOI: 10.1016/0009-2509(77)80071-7.

10. Demirel, Y., Sharma, R. \& Al-Ali, H. (2000). On the ef- fective heat transfer parameters in a packed bed. Int. J. Heat \& Mass Tran. 43, 327-332. DOI: 10.1016/S0017-9310(99)00126-X.

11. Yuen, E.H.L., Sederman, A.J., Sani, F., Alexander, P. \& Gladden, L.F. (2003). Correlations between Local Conversion and Hydrodynamics in a 3-D Fixed-Bed Exterification Process: An MRI and Lattice-Boltzmann Study. Chem. Eng. Sci. 58, 613-619. DOI: 10.1016/S0009-2509(02)00586-9.

12. Sullivan, S.P., Sani, F.M., Johns, M.L. \& Gladden, L.F. (2005). Simulation of Packed Bed Reactors Using Lattice Boltzmann Methods. Chem. Eng. Sci. 60, 3405-3418. DOI: 10.1016/j.ces.2005.01.038.

13. Sørensen, J.P. \& Stewart, W.E. (1974). Computation of Forced Convection in Slow Flow through Ducts and Packed Beds. Chem. Eng. Sci. 29 (3) 819-825. DOI: 10.1016/00092509(74)80200-9.

14. Guardo, A., Coussirat, M., Larrayoz, M.A., Recasens, F. \& Egusquiza, E. (2005). Influence of the Turbulence Model in CFD Modeling of Wall-to-Fluid Heat Transfer in Packed Beds. Chem. Eng. Sci. 60, 1733-1742. DOI: 10.1016/j.ces.2004.10.034.

15. Dixon, A.G. \& Nijemeisland, M. (2001). CFD as a Design Tool for Fixed-Bed Reactors. Ind. Eng. Chem. Res. 40, 5246-5254. DOI: 10.1021/ie001035a.

16. Calis, H.P.A., Nijenhuis, J., Paikert, B.C., Dautzenberg, F.M. \& van den Bleek, C.M. (2001). CFD Modelling and Experimental Validation of Pressure Drop and Flow Profile in a Novel Structured Catalytic Reactor Packing. Chem. Eng. Sci. 56, 1713-1720. DOI: S0009-2509(00)00400-0.

17. Magnico, P. (2003). Hydrodynamic and Transport Properties of Packed Beds in Small Tube-to-Sphere Diameter Ratio: Pore Scale Simulation Using an Eulerian and a Langrangian Approach. Chem. Eng. Sci. 58, 5005-5024. DOI: 10.1016/ S0009-2509(03)00282-3.

18. Romkes, S.J.P., Dautzenberg, F.M., van den Bleek, C.M. \& Calis, H.P.A. (2003). CFD Modelling and Experimental Validation of Particle-to-Fluid Mass and Heat Transfer in a Packed Bed at Very Low Channel-to-Particle Diameter Ratio. Chem. Eng. J. 96, 3-13. DOI: 10.1016/j.cej.2003.08.026.

19. Logtenberg, S. \& Dixon, A. (1998). Computational fluid dynamics studies of fixed bed heat transfer. Chem. Eng. Proc. 37, 7-21. DOI: 10.1016/S0255-2701(97)00032-9.

20. Dixon, A.G. \& van Dongeren, J.H. (1998). The influence of the tube and particle diameters at constant ration on heat transfer in packed beds. Chem. Eng. Proc. 37, 23-32. DOI: S0255-2701(97)00033-0.

21. ANSYS Fluent 12.0/12.1 Documentation, 2010.

22. Peters, S.T. (1998). Handbook of composites. SpringerVerlag.

23. Ergun, S. (1952). Fluid flow through packed columns. Chem. Eng. Prog. 48, 89-94.

24. Macdonald, I.F., El-Sayed, M.S., Mow, K. \& Dullien, F.A.L. (1979). Flow through porous media - the Ergun equation revisited. Ind. Eng. Chem. Fundam. 18(3), 199-208. DOI: 10.1021/i160071a001.

25. Mueller, G.E. (2010). Radial porosity in packed beds of spheres. Powd. Tech. 203, 626-633. DOI: 10.1016/j.powtec.2010.07.007.

26. Nijemeisland, M. \& Dixon, A.G. (2001). Comparison of CFD simulations to experiment for convective heat transfer in a gas-solid fixed bed. Chem. Eng. J. 82, 231-246. DOI: 10.1016/S1385-8947(00)00360-0.

27. Freiwald, M.G. \& Paterson, W.R. (1992). Accuracy of model predictions and reliability of experimental data for heat transfer in packed beds. Chem. Eng. Sci. 47, 1545-1560. DOI: 10.1016/0009-2509(92)85003-T.

28. Ding, Y.L., Wang, Z.L., Wen, D.S., Ghadiri, M., Fan, X.F. \& Parker, D.J. (2005). Solids behaviour in a gas-solid two-phase mixture flowing through a packed particle bed. Chem. Eng. Sci. 60, 5231-5239. DOI: 10.1016/j.ces.2005.04.052. 